\title{
PROGRAM “HOME VISIT” DALAM MENINGKATKAN SEMANGAT BELAJAR SISWA
}

\author{
Dwi Fitri Wiyono, Nazili Masruri \\ Fakultas Agama Islam, Universitas Islam Malang \\ Korespondensi email: dwi.fitri@unisma.ac.id
}

\begin{abstract}
ABSTRAK
Desa Jenggolo yang mayoritas siswa siswi sendiri sangat membutuhkan pendidikan di masa covid, berbagai kesulitan yag dihadapi seperti sulitnya menerima materi, terlalu susah materi yang didapatkan, sehingga membuat siswa di desa jenggolo merasa malas untuk melaksanakan pembelajaran Daring. Dampak dari kemalasan siswa siswi di Desa jenggolo yang merasa malas dengan pembelajaran Daring adalah terlalu meganggap pendidikan adalah hal biasa. Berangkat dari asumsi-asumsi di atas dapat diatasi dengan salah satu metode yang dipandang cukup efektif yaitu metode layanan home visit dalam meningkatkan minat belajar maupun santri. Penelitian dilaksanakan secara langsung pada tanggal 1 Februari 2021 - 28 Februari 2021 di Jl Kalinyamat, Rt 03 Rw 03 Desa Jenggolo, Kecamatan Kepanjen, Kabupaten Malang. Teknik pengumpulan data yang dilaksanakan mahasiswa yaitu dengan melakukan sosialisasi. memantapkan kemampuan pengabdian kepada masyarakat melalui metodologi ilmiah sehingga relevan dan berperan dalam menunjang keberhasilanPendidikan di Indonesia melalui kegiatan Home Visit yang dijadikan salah satu Program Unggulan Mahasiswa KSM Universitas Islam Malang. Meskipun adanya kesadaran masyarakat akan kesehatan dan penggunaan masker setiap melaksanakan keluar dan kegiatan diluar rumah.
\end{abstract}

Kata Kunci: home visit; semangat belajar.

\section{PENDAHULUAN}

Pendidikan merupakan jalan yang efektif dalam upaya pengembangan kemampuan manusia. Melalui pendidikan siswa dibina untuk mengembangkan kemampuan yang dimiliki (Puspitasari, Nur Aini \& Hidayatullah, 2020; Zakaria et al., 2019). Dalam pendidikan perlu adanya komunikasi yang optimal antara guru dan wali murid agar terciptanya kesuksesan dalam tujuan belajar siswa (Heriyawati et al., 2014; Nasor, 2014; Faruqi, 2018). Di masa covid pendidikan memerlukan bantuan pembelajaran daring yang dilaksanakan di rumah masing-masing (Sadikin \& Hamidah, 2020; Handarini \& Wulandari, 2020). Banyak siswa yang kesusahan dalam menerima pembelajaran yang telah diberikan oleh guru maka dari itu siswa butuh bantuan belajar dengan cara mengembangkan inovasi untuk mendapatkan pendidikan salah satunya pengembangan pembelajaran home visit (Nurrita, 2018).

Home visit atau kunjungan ke rumah merupakan kegiatan yang mendapatkan data, kemudahan dan komitmen bagi peserta didik melalui pertemuan dengan orang tua atau keluarga (Febriana, 2011). Dengan demikian Home visit dapat disimpulkan bahwa bantuan pembelajaran yang mana seorang guru datang ke rumah untuk membantu siswa dalam proses pembelajaran. Dengan memberikan tujuan dalam membantu untuk memperoleh berbagai keterangan atau data yang diperlukan untuk membantu siswa dalam memahami lingkungan atau pemecahan masalah yang telah dialami siswa saat belajar dari rumah. 
Dalam pembelajaran daring sering bermunculnya permasalahan-permasalahan yang lahir dari siswa maka dari itu di perlu adanya inisiatif guru untuk datang ke rumah siswa.

Desa Jenggolo yang mayoritas siswa siswi sendiri sangat membutuhkan pendidikan di masa covid, berbagai kesulitan yang dihadapi seperti sulitnya menerima materi, terlalu susah materi yang didapatkan, sehingga membuat siswa di desa jenggolo merasa malas untuk melaksanakan pembelajaran Daring. Dampak dari kemalasan siswa siswi di Desa jenggolo yang merasa malas dengan pembelajaran Daring adalah terlalu menganggap pendidikan adalah hal biasa.

Dapat dimengeri bahwa banyak akibat yang semakin meluas dari pembelajaran Daring pada masa Covid. Sebagai mana yang kita ketahui bahwa pendidikan meruoakan salah satu jalan ilmu yang mudah didapatkan, bahkan dipercayai sebagai besar masyarakat sebagai salah satu tempat untuk belajar, berlatih kecakapan, menyerap ilmu bahkan proses mendewasakan.

Berangkat dari asumsi-asumsi di atas dapat diatasi dengan salah satu metode yang dipandang cukup efektif yaitu metode layanan home visit dalam meningkatkan minat belajar maupun santri sekitar dengan melalui berbagai pembelajaran, berdasarkan permasalahan yang di hadapi siswa Desa Jenggolo mengakibatakan partisipasi belajar yang kurang, sehingga Mahasiswa KSM Universitas Islam Malang mengkaji Program home visit dalam meningkatakan belajar siswa Desa Jenggolo dengan melaksanakan berbagai sosialisasi kegiatan.

\section{METODE}

Pengabdian ini dilaksanakan oleh mahasiswa kandidat Sarjana Mengabdi (KSM) Tematik berbasis Keilmuan dan Domisili Universitas Islam Malang, Kelompok KSM Tematik Desa Jenggolo Tahun 2021 Akademik 2021/2022. Berkolaborasi dengan Dosen Pembimbing Lapangan, dilaksanakan secara langsung pada tanggal 1 Februari 2021 - 28 Februari 2021 di Jl Kalinyamat, Rt 03 Rw 03 Desa Jenggolo, Kecamatan Kepanjen, Kabupaten Malang.

Metode dalam program ini menggunakan pengunaan pendekatan kualitatif dengan metode deskriptif. Menurut Sugiyono (2019) menyatakan bahwa Penelitian Kualitatif sebagai human instrument, berfungsi menetapkan focus penelitian, memilih informasi sebagai sumber data, melakukan pengumpulan data, menafsirkan data dan membuat kesimpulan atas semuanya. Jenis penelitian yang dilakukan yaitu kajian Fenologis fkus terhadap kegiatan, mengungkapkan permasalahan dan memaparkan data. Sedangkan Menurut Nazir \& Sikmumbang (2009) metode diskripsi adalah suatu metode yang meneliti suatu kelompok antara lain manusia, suatu objek, suatu kondisi, maupun suatu sistem pemikiran yang pada masa sekarang.

Teknik pengumpulan data yang dilaksanakan mahasiswa yaitu dengan melakukan sosialisasi terhadap Kepala Desa jenggolo agar mendapatkan persetujuan mengenai program yang didapatkan, Selanjutnya masuk tahap sosialisasi terhadap masyarakat mengenai kesulitan belajar anak di rumah, dan mewawancari beberapa warga, sehingga mahasiswa memberikan solusi mengenai permasalahan tersebut. Sehingga akan melaksanakan tahap pendampingan siswa desa Jenggolo dalam pemberian solusi yaitu melksankan home visit dengan berbagai macam belajar.

Tabel 1. Roadmap Program Pengabdian

\begin{tabular}{llll}
\hline \multicolumn{1}{c}{$\begin{array}{c}\text { Metode } \\
\text { Pengabdian }\end{array}$} & \multicolumn{1}{c}{ Kegiatan } & \multicolumn{1}{c}{ Tujuan } & \multicolumn{1}{c}{ Output } \\
\hline Sosialisasi & Melaksanakan Sosialisasi kepada & $\begin{array}{l}\text { Agar banyaknya } \\
\text { partisipasi dan } \\
\text { Mengenai Minat }\end{array}$ & $\begin{array}{l}\text { Adanya Antusias } \\
\text { bahwa akan }\end{array}$ \\
Belajar Siswa. & $\begin{array}{l}\text { bapak Kepala Desa untuk } \\
\text { melaksanakan kegiatan belejar yang } \\
\text { akan disosialisasikan kepada siswa }\end{array}$ & & $\begin{array}{l}\text { diadakanya home } \\
\text { visit. Kegiatan, dan }\end{array}$
\end{tabular}




\begin{tabular}{|c|c|c|c|c|}
\hline $\begin{array}{c}\text { Metode } \\
\text { Pengabdian } \\
\end{array}$ & Kegiatan & Tujuan & Output & $\begin{array}{c}\text { Waktu } \\
\text { Pelaksanaan }\end{array}$ \\
\hline \multirow{11}{*}{$\begin{array}{l}\text { Pendampingan } \\
\text { Kegiatan } \\
\text { Pembelajaran }\end{array}$} & $\begin{array}{l}\text { dan murid apabila akan diadakan } \\
\text { belajar dengan mahasiswa datang } \\
\text { kerumah rumah. }\end{array}$ & $\begin{array}{l}\text { siswa Desa } \\
\text { jenggolo. }\end{array}$ & \multirow{11}{*}{$\begin{array}{l}\text { Adanya } \\
\text { Partisipasi yang } \\
\text { kuat, dalam } \\
\text { pelaksanaan } \\
\text { pembelajaran } \\
\text { sehingga } \\
\text { berjalan dengan } \\
\text { baik }\end{array}$} & $\begin{array}{l}\text { sosialisasi } \\
\text { dirumah ibu } \\
\text { Sani' }\end{array}$ \\
\hline & Melaksanakan Pembelajaran melalui & Agar Memiliki & & Kegiatan \\
\hline & kegiatan home visit di rumah Bapak & Semangat bahwa & & dilaksanakan 1 \\
\hline & Samsul dan Ibu Sani' dengan & pedidikan sangat & & Minggu $4 \times$ \\
\hline & Mematuhi protkol kesehatan. & penting dalam & & selama Satu \\
\hline & & kehidupan & & Bulan \\
\hline & Melaksankan Senam belajar kepada & sehingga tetap & & Pengabdian. \\
\hline & siswa TK Harapan Bunda di & melaksanakan & & \\
\hline & Lapangan Rumah Bapak Samsul & belajar meski & & \\
\hline & & $\begin{array}{l}\text { adanya wabah } \\
\text { Covid-19 vang }\end{array}$ & & \\
\hline & & semakin meluas. & & \\
\hline
\end{tabular}

\section{HASIL DAN PEMBAHASAN}

Konsepsi luas pengabdian kepada masyarakat sebagai pengamalan ilmu pengetahuan, teknologi, dan seni dapat meliputi pengertian-pengertian sebagai berikut:

Pertama, Adanya sosialisasi yang dikembangkan mahasiswa melalui bapak kepala desa yang dilaksankan pada tanggal 2 Februari 2021 Mengenai program kerja yaitu Home Visit Kepala Desa menyampaikan apabila banyak kurangnya siswa dalam mina belajar sehingga membuat siswa merasa malas akan proses pembelajaran daring yang telah dilaksanakan selama masa COVID-19, sehingga mahasiswa memberikan solusi dari program kerja home visid yang akan diadakan di Desa Jenggolo dengan memebrikan berbagai materi dan bentuk kegiatan menyenangkan, sihinggan bertujuan agar siswa memiliki minat yang tinggi terdapat kegiatan pembelajaran daring, berbagai model pembelajaran juga diterpakan dalam melaksanakan proses home visid.

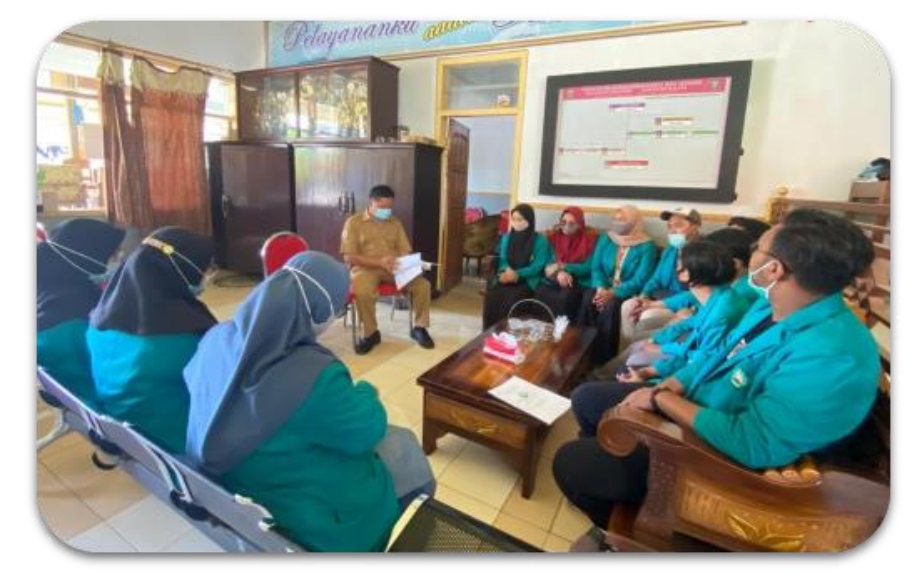

Gambar 1. Sosialisasi bersama Kepala Desa

Sosialisasi bukan hanya dilaksanakan kepada Kepala desa, namun persetuajuan kepada desa didapatkan sehingga Mahasiswa mampu terjun dalam lapangan dan mensosialisasikan ke orang tua siswa apabila akan ada program home visit yang diselenggarakan mahasiswa selama masa pengabdian yang bertujuan agar tumbuhnya minat belajar siswa pada masa Pandemi COVID-19. 


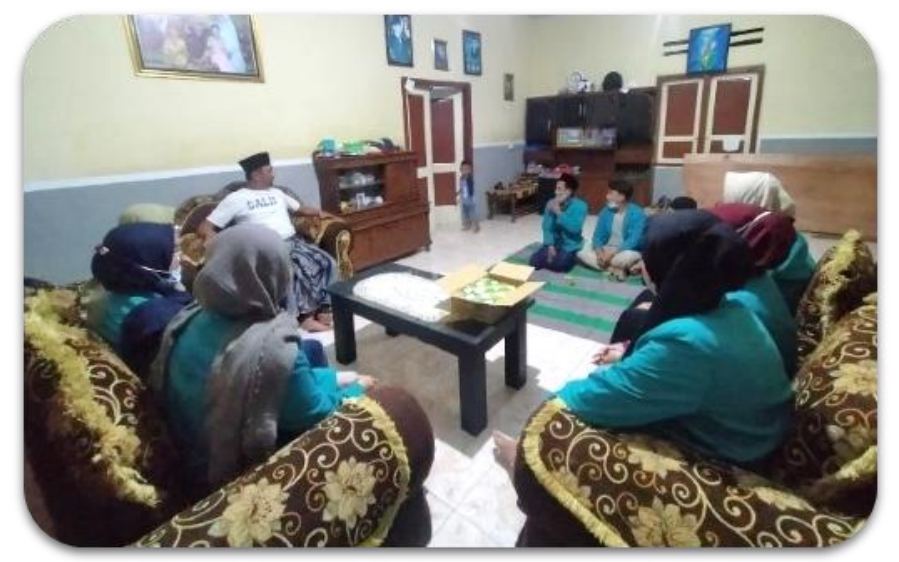

Gambar 2. Sosialisasi bersama Salah Satu Orang Tua Siswa

Kedua, Adanya kegiatan pendampiangan yang merupakan kegiatan lanjutan yang dilaksankan 1 minggu 4 kali setiap pukul 07.00-08.00 untuk mendapatkan hasil dari program home visit yang telah dirancang, kegitan home visit dilaksankan dirumah Bapak Sholeh kegitan mengajar dilaksanakan dengan menggunakan metode yang mudah dipahami siswa salah satunya dengan menggunakan Metode Cermah, karna mayoritas Siswa Desa Jenggolo adalah Siswa Sekolah Dasar (SD) maka kegiatan pembelajaran dilaksanakan dengan menggunakan metode yang lebih mudah, bukan hanya menggunakan metode Ceramah namun menggunakan metode bercerita , dimana mahasiswa menceritakan pengalaman pada masa belajar yang pernah dihadapi sehingga siswa tidak merasa jenuh dan bosan.

Kegiatan belajar bukan hanya melaksaanakan materi belajar siswa, namun juga memberikan bimbingan keagamaan agar terbentuknya ahlak yang baik kegiatan pembelejaaran keagamaan, yang dilaksanakan di dua tempat yaitu dilaksanakan dirumah bapak Samsul dan Ibu Sanii' setiap 1 minggu 4 kali pukul 14.00-16.00 . Kegiatan mengajar sangat memberikan partiisipasi yang tinggi. Kegiatan Home visit dilaksanakan bukan hanya melaksanakan belajar namun dilaksanakanya Bernyanyi bersama dengan menggunkan Bahasa arab, Menghafal Surat Pendek dan Menlaksanakan Tanya Jawab yang membuat siswa termotifasi.

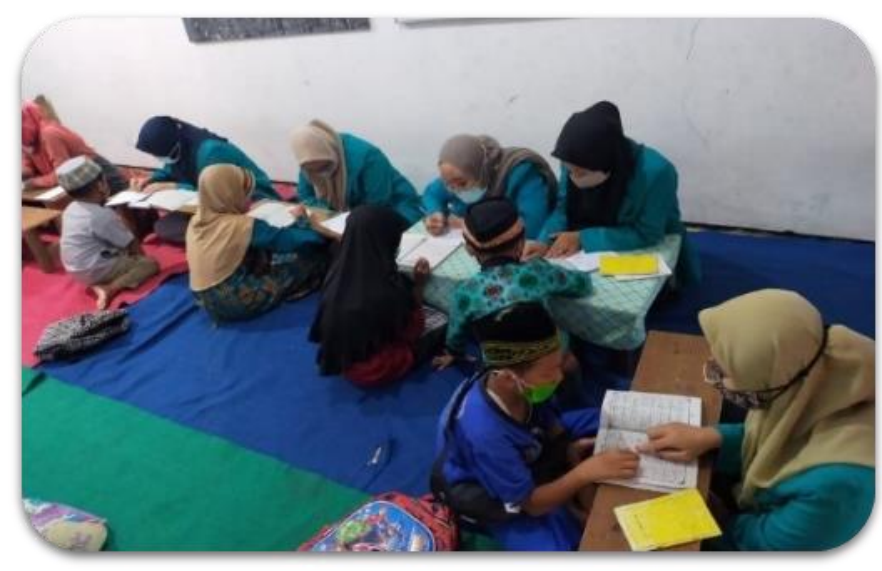

Gambar 3. Melaksanakan Home Visit

Keempat, Kegiatan senam bersama yang dilaksanakan mahasiswa KSM Universitas Islam Malang sebagai proram akhir mahasiswa untuk membentuk imun tubuh agar tetap sehat yang dilaksanakan Rabu, 23 Februari 2021 Kegiatan Olah raga bersama di TK Harapan bunda dilaksanakan dengann banyak antusisas Orang tua dan murit, namun dalam kegiatan 
ini terdapat beberapa kendala yang menjadi faktor yang perlu diperhatikan masrakat setempat yaitu penggunaan masker saat melksanakan kegiatan di luar rumah.

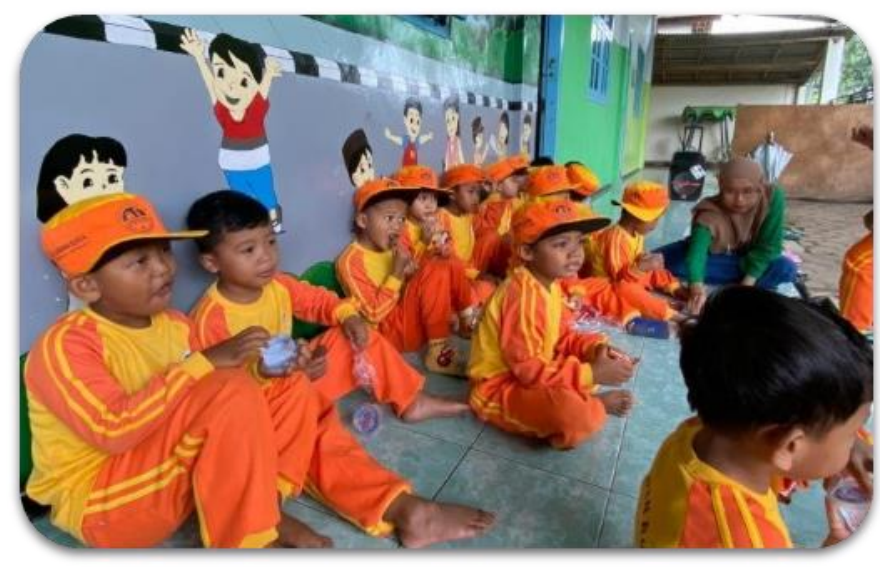

Gambar 4. Melaksanakan Senam Bersama

Perlu disadari bahwa sejalan dengan tantangan dan permasalahan yang dihadapi oleh bangsa kita, maka peranan yang diharapkan perguruan tinggi akan semakin penting artinya dalam rangka menunjang keberhasilan Pendidikan daerah. Sehubungan dengan itu, perlu ada pemikiran dan usaha secara konsepsional yang sepadan dengan harapan tersebut untuk memantapkan kemampuan pengabdian kepada masyarakat melalui metodologi ilmiah sehingga relevan dan berperan dalam menunjang keberhasilanPendidikan di Indonesia melalui kegiatan Home Visit yang dijadikan salah satu Pro gram Unggulan Mahasiswa KSM Universitas Islam Malang. Meskipun adanya kesadaran masyarakat akan kesehatan dan penggunaan masker setiap melksanakan keluar dan kegiatan di luar rumah.

\section{KESIMPULAN}

Kegiatan Kandidat Sarjana Mengabdi yang dilaksanakan Penelitian secara langsung pada tanggal 1-28 Februari 2021 di Jalan Kalinyamat, RT 03 RW 03 Desa Jenggolo, Kecamatan Kepanjen, Kabupaten Malang. Melalui kegiatan Program Unggulan yang dilaksanakan Mahasiswa KSM UNISMA yaitu Home Visit. Yang mendapatkan Partisipasi baik dari masyarakat, namun melalui kendala kurangnya penggunaan masker dalam kegiatan sehingga siswa memberikan sosialisasi pentingnya penggunaan masker dalam pelaksanaan kegiatan diluar rumah. Pentingnya Peran Kandidat sarjana mengabdi diperlukan masyarakat karna memberikan bantuan pendidkan Melalui kegiatan Home Visit.

\section{DAFTAR RUJUKAN}

Faruqi, D. (2018). Upaya Meningkatkan Kemampuan Belajar Siswa Melalui Pengelolaan Kelas. Evaluasi, 2(1), 294-310. https://doi.org/10.32478/evaluasi.v2i1.80

Febriana, A. (2011). Penerapan Model Pembelajaran Kooperatif Tipe Make A Match untuk Meningkatkan Kualitas Pembelajaran IPS Siswa Kelas V SDN Kalibanteng Kidul 01 Kota Semarang. Jurnal Kreatif: Jurnal Kependidikan Dasar, 1(2), 151-161. https://doi.org/10.15294/kreatif.v1i2.1678

Handarini, O. I., \& Wulandari, S. S. (2020). Pembelajaran Daring Sebagai Upaya Study From Home (SFH) Selama Pandemi Covid 19. Jurnal Pendidikan Administrasi Perkantoran (JPAP), 8(3), 496-503. https://doi.org/10.1093/fampra/cmy005

Heriyawati, D. F., Sulistyo, T., \& Sholeh, A. (2014). the Implementation of Content-Based Approach in Improving Academic Writing Skills of Efl Students. LiNGUA: Jurnal IImu Bahasa Dan Sastra, 9(2), 136-144. https://doi.org/10.18860/ling.v9i2.2735 
Nasor, M. (2014). Teknik Komunikasi Guru Dan Siswa Dalam Peningkatan Prestasi Siswa. Ijtimaiyya, 7(2), 67-86. https://doi.org/10.24042/ijpmi.v7i2.928

Nazir, M., \& Sikmumbang, R. (2009). Metode Penelitian (R. Sikumbang (ed.)). Ghalia Indonesia.

Nurrita, T. (2018). Pengembangan Media Pembelajaran Untuk Meningkatkan Hasil Belajar Siswa. MISYKAT: Jurnal Ilmu-Ilmu Al-Quran, Hadist, Syari'ah Dan Tarbiyah, 3(1), 171187. https://doi.org/10.33511/misykat.v3n1.171

Puspitasari, N. A., \& Hidayatullah, S. (2020). Peningkatan wawasan penerapan model pembelajaran berorientasi HOTS (Higher Order Thinking Skill) bagi guru MTs dan MA. Jurnal Inovasi Hasil Pengabdian Masyarakat (JIPEMAS), 3(2), 128-135. https://doi.org/10.33474/jipemas.v3i2.6131

Sadikin, A., \& Hamidah, A. (2020). Pembelajaran Daring di Tengah Wabah Covid-19. Biodik: $\begin{array}{llll}\text { Jurnal Ilmiah Pendidikan Biologi, } & \text { 6(2), }\end{array}$ https://doi.org/10.22437/bio.v6i2.9759

Sugiyono. (2019). Metode Penelitian Kuantitatif Kualitatif dan R\&D. Alfabeta.

Zakaria, Z., Setyosari, P., Sulton, \& Kuswandi, D. (2019). The effect of art-based learning to improve teaching effectiveness in pre-service teachers. Journal for the Education of Gifted Young Scientists, 7(3), 531-545. https://doi.org/10.17478/jegys.606963 